\title{
Renal function impairment induced by change in posture in patients with cirrhosis and ascites
}

\author{
M BERNARDI, COSTANZA SANTINI, F TREVISANI, M BARALDINI, \\ A LIGABUE, AND G GASBARRINI
}

From the Cattedra di Patologia Speciale Medica III, Università di Bologna, Bologna, Italia, and the Laboratorio di Analisi, Ospedale M Malpighi, Bologna

SUMmaRY The assumption of upright posture by patients with liver cirrhosis leads to striking activation of adrenergic and renin-angiotensin systems. The tilting-induced modifications in renal function of eight healthy controls and 14 untreated patients with liver cirrhosis and ascites were related to plasma concentrations of noradrenaline, renin activity and aldosterone. All patients had preserved renal blood perfusion. All parameters were evaluated during bed rest for two hours and in the sitting posture for one hour. Basal plasma renin activity $(0 \cdot 1>p>0 \cdot 05)$, aldosterone and noradrenaline concentrations $(p \leqslant 0.01)$ were raised in cirrhotics. The renal function tests (creatinine clearance, filtered sodium, tubular rejection fraction, urinary sodium excretion) were significantly reduced in cirrhosis. Under basal conditions, in cirrhotic patients tubular rejection fraction and urinary sodium excretion were inversely related to both noradrenaline and aldosterone concentrations. After tilting, the noradrenaline and aldosterone integrated outputs $(\Sigma \Delta)$ were significantly greater in cirrhosis. All renal function tests significantly decreased in cirrhotics, whereas creatinine clearance only significantly decreased in controls. Patient's tubular rejection fraction of sodium and sodium excretion were related to $\Sigma \Delta$ aldosteronaemia $(\mathrm{r}=-0.72 ; \mathrm{p}<0.01)$, but no longer to $\Sigma \Delta$ plasma noradrenaline.

Bed rest seems to enhance the effect of diuretics in patients with cirrhosis with ascites. ${ }^{1}$ Furthermore in normal subjects an upright posture reduces renal perfusion and urinary sodium excretion ${ }^{2}{ }^{3}$ despite autoregulation of renal blood flow and glomerular filtration rate over a wide range of arterial pressure. ${ }^{4}$ The precise mechanism(s) of these changes is not entirely clear, but several findings point to the adrenergic and renin-angiotensin systems as very important factors. ${ }^{2} 35$

Plasma renin concentration ${ }^{6}$ and activity ${ }^{7-11}$ and plasma noradrenaline concentration ${ }^{9-13}$ have often been found to be increased in recumbent cirrhotics with ascites. Both the renin-angiotensin and adrenergic systems exhibit an enhanced response to orthostatic stimulation in cirrhosis. ${ }^{10}$ Therefore, changes in posture in cirrhotic patients could be followed by greater change in renal function than those observed in normal subjects.

\footnotetext{
Address for correspondence: Professor Mauro Bernardi, Cattedra di Patologia Speciale Medica III, Policlinico S Orsola, Via Massarenti, 9, 40138 Bologna, Italy.

Received for publication 17 July 1984
}

We have quantified the changes of renal function in cirrhotic patients with ascites induced by the changes in posture, and investigated their pathophysiology.

\section{Methods}

\section{PATIENTS}

This study was carried out on 14 male patients with cirrhosis and ascites (age range 38-65 years) and eight healthy controls matched for sex and age. Cirrhosis had been diagnosed by biopsy and/or laparoscopy in all cases and all patients had portosystemic shunts, ascertained by endoscopy, or dilated portal vein, ascertained by ultrasonography. In six cases the cirrhosis was caused by alcohol excess, in six by hepatitis B virus and in two it was unknown. No patient had heart failure, hyperazotemic renal disease, hypertension, diabetes, peripheral neuropathy, or recent gastrointestinal haemorrhage (at least two months) and none was taking steroids, prostaglandin inhibitors, amines or anti-hypertensive drugs. Diuretic treat- 
ment, when given (nine cases), was stopped one week before the investigation. Table 1 illustrates main liver function and basal renal function tests in the patients studied.

This study was undertaken according to the declaration of Helsinki, and informed consent was obtained in all cases.

\section{PROTOCOL OF THE STUDY}

Controls and patients underwent a seven day equilibration period during which they assumed a diet providing $40 \mathrm{mmol} /$ day of sodium and 80 $\mathrm{mmol} /$ day of potassium. Alcohol intake had ceased at least one year before the study in the alcoholics and it was prohibited during the equilibration period in the controls. After an overnight fast, studies were started at $8 \mathrm{am}$, with a two hour bed rest in a quiet room, during which endogenous creatinine clearance was measured. Blood samples for creatinine and sodium concentration and haematocrit determinations were obtained at the midpoint. An indwelling venous catheter was inserted and samples were taken at the end of the rest period for the determination of plasma renin activity, plasma aldosterone concentration and plasma noradrenaline concentration. Urine samples were collected throughout. The subjects then assumed and maintained a sitting posture in bed, with their legs dangling, and again blood was taken for plasma renin activity, plasma aldosterone concentration, and plasma noradrenaline concentration after 10,30 , and 60 minutes. Urine collection for a second clearance period started at the time of the change of posture and lasted $60-90$ minutes. Blood for creatinine and sodium concentration and haematocrit determinations was sampled after 30 minutes. Arterial pressure was determined at the midpoints of the two endogenous creatinine clearance periods. The withdrawn blood volume was replaced each time with Ringer's solution.

\section{DETERMINATIONS}

Peripheral venous blood was collected in icecooled tubes with sodium EDTA as anticoagulant ( 2 drops of $10 \%$ solution for $10 \mathrm{ml}$ of blood). After centrifugation at $4^{\circ} \mathrm{C}, 0 \cdot 1 \mathrm{ml}$ of sodium EDTA $5 \%$, and $0.1 \mathrm{ml}$ of sodium metabisulphite $10 \%$ were added. Noradrenaline concentration was determined using the flurorometric method of Renzini $e t$ $a l,{ }^{14}$ using mercaptoethanol instead of dimercaptopropranolol. Plasma concentrations were expressed as $\mathrm{ng} / \mathrm{l}$. Values for 16 healthy supine control subjects under identical experimental conditions of sodium intake ranged from 95-314 $\mathrm{ng} / \mathrm{l}$.

Blood was collected in ice-cooled polyethylene tubes with disodium EDTA as anticoagulant (1 mg/ $\mathrm{ml}$ of blood). Plasma renin activity was determined by radioimmunoassay for angiotensin $I$ and calculated using the difference between angiotensin I present in $1 \mathrm{ml}$ plasma incubated with dimercaprol and 8-hydroxyquinolone for three hours at $37^{\circ} \mathrm{C}, \mathrm{pH} 6.6$, and that present in $1 \mathrm{ml}$ plasma maintained at $4^{\circ} \mathrm{C}$ under the same conditions. Angiotensin I was quantified using a specific antibody (Lepetit SpA) with a mixture of charcoal dextrane as separating agent. Plasma renin activity values were expressed as $\mathrm{ng} / \mathrm{ml} / \mathrm{h}$.

Aldosterone concentration was determined by radioimmunoassay using a specific antibody (Abbot). $1 \mathrm{ml} 25 \%$ polyethylene glycol was used as separating agent. Plasma aldosterone concentration values were expressed as $\mathrm{pg} / \mathrm{ml}$. Values for 21 healthy supine control subjects under identical experimental conditions of sodium intake ranged

Table 1 Liver function and basal renal function tests in the cirrhotic patients

\begin{tabular}{|c|c|c|c|c|c|c|c|}
\hline Patient & $\begin{array}{l}\text { Albumin } \\
(g / d l)\end{array}$ & $\begin{array}{l}\text { Bilirubin } \\
(m g / d l)\end{array}$ & $\begin{array}{l}\text { Prothrombin } \\
\text { activity }(\%)\end{array}$ & $\begin{array}{l}C_{\text {creat }} \\
(\mathrm{ml} / \mathrm{min})\end{array}$ & $\begin{array}{l}F_{\mathrm{Na}} \\
(\mathrm{mmol} / \mathrm{min})\end{array}$ & $\begin{array}{l}T R F_{\mathrm{Na}} \\
(\%)\end{array}$ & $\begin{array}{l}U_{N a} V \\
(\mathrm{mmol} / \mathrm{h})\end{array}$ \\
\hline 1 & $2 \cdot 91$ & 0.8 & 57 & 111 & $15 \cdot 42$ & 0.07 & 0.68 \\
\hline 2 & $3 \cdot 0$ & $1 \cdot 1$ & 72 & 97 & $13 \cdot 87$ & 0.26 & $2 \cdot 08$ \\
\hline 3 & $2 \cdot 47$ & $2 \cdot 3$ & 52 & 51 & $6 \cdot 98$ & 0.07 & $0 \cdot 30$ \\
\hline 4 & $3 \cdot 21$ & $1 \cdot 2$ & 70 & 66 & $9 \cdot 11$ & 0.26 & $1 \cdot 40$ \\
\hline 5 & $2 \cdot 80$ & 2.9 & 48 & 64 & $8 \cdot 89$ & $0 \cdot 16$ & 0.64 \\
\hline 6 & $3 \cdot 35$ & $1 \cdot 5$ & 66 & 113 & $15 \cdot 70$ & 0.89 & $6 \cdot 24$ \\
\hline 7 & $2 \cdot 78$ & $3 \cdot 1$ & 68 & 119 & $16 \cdot 54$ & 0.47 & $4 \cdot 62$ \\
\hline 8 & $2 \cdot 86$ & 0.9 & 71 & 84 & $12 \cdot 01$ & 0.41 & $2 \cdot 88$ \\
\hline 9 & $3 \cdot 51$ & 0.9 & 77 & 61 & $7 \cdot 86$ & 0.44 & $2 \cdot 92$ \\
\hline 10 & $2 \cdot 01$ & $3 \cdot 4$ & 35 & 42 & 5.37 & 0.57 & $1 \cdot 74$ \\
\hline 11 & $2 \cdot 41$ & $1 \cdot 7$ & 40 & 64 & 8.44 & $0 \cdot 14$ & 0.71 \\
\hline 12 & $2 \cdot 90$ & $1 \cdot 2$ & 68 & 112 & $15 \cdot 23$ & 0.65 & $5 \cdot 18$ \\
\hline 13 & $2 \cdot 13$ & $2 \cdot 9$ & 32 & 90 & $7 \cdot 50$ & 0.05 & 0.40 \\
\hline 14 & $2 \cdot 82$ & $1 \cdot 6$ & 59 & 91 & $11 \cdot 83$ & 0.35 & 1.06 \\
\hline
\end{tabular}


from $0.68-1.99 \mathrm{ng} / \mathrm{ml} / \mathrm{h}$ for plasma renin activity and from $32-150 \mathrm{pg} / \mathrm{ml}$ for plasma aldosterone concentration.

Plasma noradrenaline concentration, plasma renin activity, and plasma aldosterone concentration after the assumption of the sitting posture have been expressed as the sum of the differences $(\Sigma \Delta)$ between plasma concentrations at $10\left(\mathrm{X}_{10}\right)$, $30\left(\mathrm{X}_{30}\right)$ and $60\left(\mathrm{X}_{60}\right)$ minutes and basal values $\left(\mathrm{X}_{\mathrm{B}}\right)$ :

$$
\Sigma \Delta=\left(\mathrm{X}_{10}-\mathrm{X}_{\mathrm{B}}\right)+\left(\mathrm{X}_{30}-\mathrm{X}_{\mathrm{B}}\right)+\left(\mathrm{X}_{60}-\mathrm{X}_{\mathrm{B}}\right)
$$

\section{STUDY OF RENAL FUNCTION}

Plasma and urinary concentrations of creatinine were measured using a colorimetric method (Boehringer Mannheim $\mathrm{GmbH}$ ). Endogenous creatinine clearance $\left(\mathrm{C}_{\text {creat }}\right)$ was calculated with the usual formula $U_{\text {creat }} / P_{\text {creat }} \times V$, where $U_{\text {creat }}$ and $P_{\text {creat }}$ are the urine and plasma concentrations of creatinine and $\mathrm{V}$ is the urine volume. Creatinine clearance has been considered as a measure of glomerular filtration rate. The filtered sodium $\left(\mathrm{F}_{\mathrm{Na}}\right)$ was obtained by $\mathrm{P}_{\mathrm{Na}} \times \mathrm{C}_{\text {creat }}$, where $\mathrm{P}_{\mathrm{Na}}$ is the plasma sodium concentration. The tubular rejection fraction of sodium $\left(\mathrm{TRF}_{\mathrm{Na}}\right)$ was calculated by: $\mathrm{U}_{\mathrm{Na}} \mathrm{V} \times 100 / \mathrm{C}_{\text {creat }} \times \mathrm{P}_{\mathrm{Na}}$, where $\mathrm{U}_{\mathrm{Na}} \mathrm{V}$ is the urine sodium excretion. The difference between sitting posture and basal values was expressed as $\Delta$.

Arterial pressure was measured by sphigmomanometry, carried out on all occasions by the same operator. Values were expressed as mean pressure (mean AP $=$ diastolic $+\frac{1}{3}$ pulse pressure).

\section{OTHER DETERMINATIONS}

Plasma and urine sodium concentrations were evaluated by flame photometry. Packed cell volume was determined by peripheral microhaematocrit technique. The per cent decrease of plasma volume during tilting compared with basal values was calculated according to: $100 /\left(100-\mathrm{H}_{1}\right)$
$\times\left(\mathrm{H}_{2}-\mathrm{H}_{1}\right) / \mathrm{H}_{2}$, where $\mathrm{H}_{1}$ and $\mathrm{H}_{2}$ are the initial and final packed cell volumes. ${ }^{15}$

\section{STATISTICAL METHODS}

Results were expressed as mean $\pm \mathrm{SE}$. Differences between controls and patients were evaluated by Wilcoxon's rank sum test; the significance of the changes induced by the change of posture within the groups was evaluated by the Wilcoxon's matched-pairs signed-ranks test. To derive correlation coefficients, linear functions were used. If the variables were logarithmically distributed, the logarithm was used.

\section{Results}

\section{BASAL CONDITIONS}

Plasma renin activity, plasma aldosterone concentration, and plasma noradrenaline concentration were found within the normal range from our laboratory in eight, nine, and seven patients respectively. Their mean values, however (Table 2 ), were significantly raised compared with the control group considered in this study.

Cirrhotics' renal function (Table 3) was characterised by reduced mean values of $\mathrm{C}_{\text {creat }}, \mathrm{F}_{\mathrm{Na}}$ (as a result of both decreased $\mathrm{C}_{\text {creat }}$ and plasma sodium concentration: $143 \cdot 16 \pm 1.92 \mathrm{mmol} / \mathrm{l}$ and $135.57 \pm 1.48 \mathrm{mmol} / \mathrm{l}$ in controls and patients respectively, $\mathrm{p}<0 \cdot 005$ ), and $\mathrm{U}_{\mathrm{Na}} \mathrm{V}$. Mean arterial pressure of cirrhotics $(82 \pm 2.56 \mathrm{mmHg})$, was lower than that of controls $(93 \pm 3 \cdot 2 \mathrm{mmHg} ; \mathrm{p}<0 \cdot 01)$.

\section{INTERRELATIONSHIPS BETWEEN PLASMA RENIN} ACTIVITY, PLASMA ALDOSTERONE

CONCENTRATION, PLASMA NORADRENALINE

CONCENTRATION AND RENAL FUNCTION

Log plasma noradrenaline concentration was significantly correlated with log plasma renin activity only in patients $(\mathrm{r}=0.67, \mathrm{p}<0.01)$.

$\log \mathrm{TRF}_{\mathrm{Na}}$ and $\log \mathrm{U}_{\mathrm{Na}} \mathrm{V}$ of cirrhotics were

Table 2 Plasma renin activity (PRA), plasma aldosterone (PAC) and noradrenaline (PNC) in controls and patients under basal conditions and after the assumption of the sitting position (mean $\pm S E$ )

\begin{tabular}{|c|c|c|c|c|}
\hline & & $P R A(n g / m l / h)$ & $P A C(\mathrm{pg} / \mathrm{ml})$ & $P N C(n g / l)$ \\
\hline \multicolumn{5}{|l|}{ Supine } \\
\hline Controls & & $0.88 \pm 0.05$ & $81 \cdot 32 \pm 3 \cdot 39$ & $184 \cdot 7 \pm 29 \cdot 7$ \\
\hline Patients & & $1.91 \pm 0.38^{\mathrm{a}}$ & $160 \cdot 29 \pm 29 \cdot 61^{c}$ & $389 \cdot 0 \pm 60 \cdot 9^{\mathrm{b}}$ \\
\hline \multicolumn{5}{|l|}{ Sitting } \\
\hline $\begin{array}{l}\text { Controls } \\
\text { Patients }\end{array}$ & $60 \mathrm{~min}$ & $\begin{array}{l}1 \cdot 28 \pm 0 \cdot 05 \\
3 \cdot 48 \pm 0 \cdot 59^{c}\end{array}$ & $\begin{array}{c}91 \cdot 26 \pm 7 \cdot 12 \\
261 \cdot 42 \pm 31 \cdot 34^{c}\end{array}$ & $\begin{array}{l}248 \cdot 7 \pm 31 \cdot 5 \\
578 \cdot 7 \pm 66 \cdot 3^{\mathrm{c}}\end{array}$ \\
\hline Controls & & $0 \cdot 95 \pm 0 \cdot 12$ & $34 \cdot 87 \pm 10 \cdot 1$ & $220 \cdot 5+29 \cdot 1$ \\
\hline Patients & $\Sigma \Delta$ & $3.34 \pm 0 \cdot 60^{\mathrm{b}}$ & $247 \cdot 83 \pm 47 \cdot 8^{c}$ & $486 \cdot 4 \pm 99 \cdot 2^{b}$ \\
\hline
\end{tabular}

a $0.1>p>0.05$. b $0.05>p>0.005 . \quad$ c $p<0.005$ or less. $\quad \Sigma \Delta=$ sum of differences. 
Table 3 Parameters exploring the renal function in controls and patients, under basal conditions and after the assumption of the sitting position (mean $\pm S E$ )

\begin{tabular}{|c|c|c|c|c|}
\hline & $C_{\text {creat }}(\mathrm{ml} / \mathrm{min})$ & $F_{\text {Na }}(\mathrm{mmol} / \mathrm{min})$ & $T R F_{N a}(\%)$ & $U_{N a} V(m m o l / h)$ \\
\hline \multicolumn{5}{|l|}{ Supine } \\
\hline Controls & $122 \cdot 5 \pm 5 \cdot 49$ & $17 \cdot 42 \pm 0 \cdot 86$ & $0 \cdot 62 \pm 0 \cdot 13$ & $4 \cdot 38 \pm 0 \cdot 68$ \\
\hline Patients & $83 \cdot 21 \pm 6 \cdot 76^{b}$ & $11 \cdot 05 \pm 0 \cdot 07^{c}$ & $0.34 \pm 0.06$ & $2 \cdot 2 \pm 0 \cdot 51^{b}$ \\
\hline \multicolumn{5}{|l|}{ Sitting } \\
\hline Controls & $110 \cdot 62 \pm 6 \cdot 10^{\beta}$ & $16 \cdot 02 \pm 0 \cdot 88^{\beta}$ & $0.43 \pm 0.09$ & $4 \cdot 22 \pm 0 \cdot 69$ \\
\hline Patients & $63 \cdot 36 \pm 7 \cdot 38^{c}$ & $8 \cdot 71 \pm 1 \cdot 02^{c \cdot \gamma}$ & $0 \cdot 18 \pm 0 \cdot 03^{h \cdot \gamma}$ & $0 \cdot 74 \pm 0 \cdot 13^{c . \gamma}$ \\
\hline Controls & $-12 \cdot 0 \pm 1 \cdot 48$ & $-1 \cdot 4 \pm 0 \cdot 2$ & $-0 \cdot 14 \pm 0 \cdot 16$ & $-0 \cdot 30 \pm 0.63$ \\
\hline Patients $\Delta$ & $-19 \cdot 0 \pm 2 \cdot 12^{\mathrm{b}}$ & $-2.97 \pm 0.47^{h}$ & $-0 \cdot 16 \pm 0 \cdot 05$ & $-1 \cdot 52 \pm 0 \cdot 46$ \\
\hline
\end{tabular}

The abbreviations used are explained in the text.

$b, \beta=0.05>p>0 \cdot 005$. c c, $\gamma=p<0.005$ or less. b.c. with respect to controls. $\beta, \gamma$, with respect to basal values.

inversely correlated with both log plasma aldosterone concentration $(r=-0.87, p<0.001$; $\mathrm{r}=-0.66, \mathrm{p}<0.01$ respectively) and $\log$ plasma noradrenaline concentration $(\mathrm{r}=-0.57, \mathrm{p}<0.05$; $r=-0.53, p<0.05)($ Fig. 1a). In controls these two variables were only related to log plasma aldosterone concentration $(r=-0.72, p<0.01$; $r=-0 \cdot 66,0 \cdot 01>p>0 \cdot 05)$.

Finally, patients' $\log \mathrm{F}_{\mathrm{Na}}$ was inversely correlated with log plasma renin activity $(\mathrm{r}=-0 \cdot 63, \mathrm{p}<0 \cdot 05)$.

\section{SITTING POSTURE}

The time course of changes in plasma noradrenaline concentration, plasma renin activity, and plasma aldosterone concentration is given in Figure 2. Their $\Sigma \Delta$ were significantly greater in patients compared with the control group (Table 2).

Statistically significant changes in $\mathrm{C}_{\text {creat }}$ and $\mathrm{F}_{\mathrm{Na}}$ occurred in controls. In contrast, statistically significant reductions in all parameters occurred in patients. Moreover, the magnitude of the changes in $\mathrm{C}_{\text {creat }}$ and $\mathrm{F}_{\mathrm{Na}}$ were significantly greater in patients than in controls (Table 3 ).

Plasma sodium concentration did not change significantly in either group. The mean arterial pressure of patients was again significantly reduced compared with controls $(81 \pm 3 \cdot 1 \mathrm{mmHg}$ and $98 \pm 2.31 \mathrm{mmHg}$ respectively; $\mathrm{p}<0.005$ ), but postural hypotension was not found in any patient. The per cent decrease in plasma volume was greater in patients $(-14 \cdot 3 \pm 2 \cdot 1 \%)$ than in controls $(-6 \cdot 81 \pm 1 \cdot 98 \%, \mathrm{p}<0.05)$.

INTERRELATIONSHIPS BETWEEN PLASMA NORADRENALINE, PLASMA RENIN ACTIVITY, PLASMA ALDOSTERONE CONCENTRATION, AND RENAL FUNCTION

No correlation was found between $\log \Sigma \Delta$ plasma noradrenaline concentration and $\log \Sigma \Delta$ plasma renin activity both in patients and controls.

No relationship between $\Delta \mathrm{TRF}_{\mathrm{Na}}$ nor $\Delta \mathrm{U}_{\mathrm{Na}} \mathrm{V}$ and $\log \Sigma \Delta$ plasma noradrenaline concentration was found in either controls or cirrhotics. On the contrary, $\log \Sigma \Delta$ plasma aldosterone concentration was significantly correlated with $\triangle \mathrm{TRF}_{\mathrm{Na}}$ in controls $(r=-0.65 ; 0.1>p>0.05)$ and with both $\Delta \mathrm{TRF}_{\mathrm{Na}}(\mathrm{r}=-0.72 ; \mathrm{p}<0.01)$ and $\Delta \mathrm{U}_{\mathrm{Na}} \mathrm{V}$ $(\mathrm{r}=-0.67 ; \mathrm{p}<0.01)$ in patients (Fig. $1 \mathrm{~b})$.

Patients' $\Delta \mathrm{F}_{\mathrm{Na}}$ was again related to $\log \Sigma \Delta$ plasma renin activity $(r=-0.74 ; \mathrm{p}<0 \cdot 01)$.

\section{Discussion}

We have shown for the first time that the assumption of the sitting position by patients with cirrhosis and ascites leads to important changes in their renal function. These involve both the parameters directly related to intrarenal haemodynamics, such as glomerular filtration rate and filtered sodium, and tubular sodium handling. The greater the reduction of glomerular filtration rate in cirrhotics suggests a marked fall in renal perfusion. This can be attributed to (a) the reduction in effective volaemia and (b) the enhanced stimulation of the vasoactive systems evaluated in this study. The first of these mechanisms is suggested by the fact that there was a greater per cent decrease in plasma volume in cirrhotics than in controls. This implies an increased loss of protein-free fluid through dependent vascular beds. ${ }^{15}$ Also redistribution of blood flow within a low resistance arterial system $^{16}{ }^{17}$ and further gravity-induced splanchnic pooling can be assumed, even though it was not possible to show this in our patients.

The second of these mechanisms can be attributed to the activity of the adrenergic and renin-angiotensin systems. As has already been 
Fig. 1 (a) Showing the correlation of log plasma noradrenaline (PNC) and log plasma aldosterone (PAC) concentrations with log tubular rejection fraction of sodium $\left(T R F_{N a}\right)$ in cirrhotic patients under basal conditions. (b) Showing the correlation of log $\Sigma \triangle P N C$ and $\log \Sigma \triangle P A C$ with $\triangle T R F_{N a}$ in cirrhotic patients after the assumption of the sitting posture.
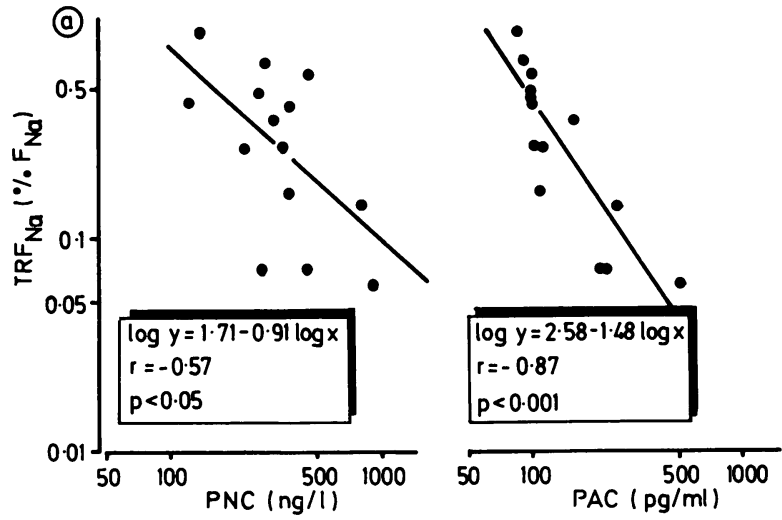

$$
\text { (b) }
$$
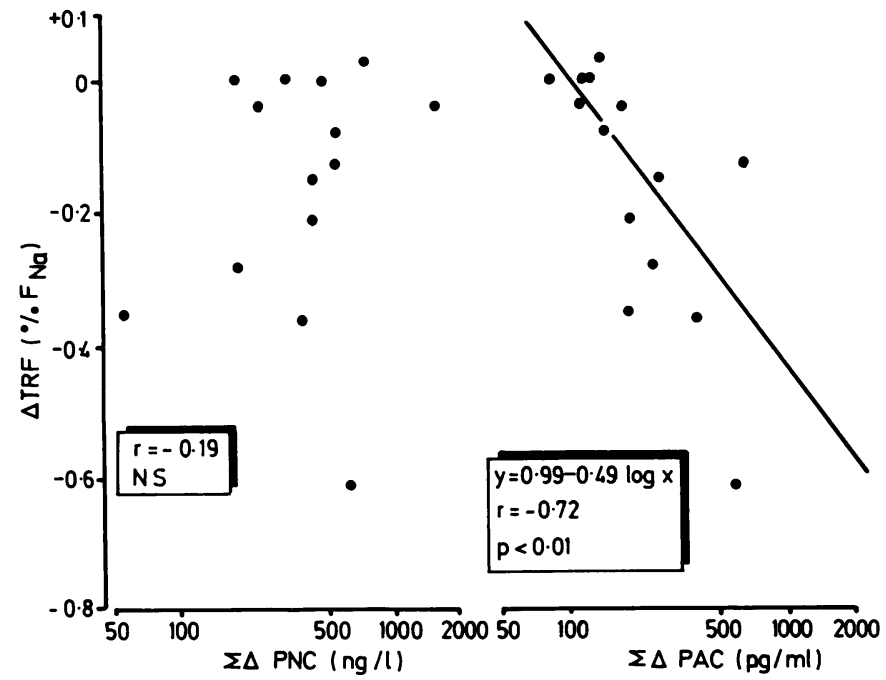

noted in previous papers, ${ }^{10-13} 18-20$ a number of cirrhotic patients in the present study had increased plasma noradrenaline concentration and plasma renin activity under basal conditions. As expected, ${ }^{7910}$ the change in posture led to an increased stimulation of both systems. The main cause of adrenergic activation was probably the reduction in effective volaemia, with consequent stimulation of arterial and venous baroreceptors. ${ }^{1012} 13$ Because the prevalent intrarenal vascular receptors belong to the alphaadrenergic type ${ }^{21}$ the striking increase in plasma noradrenaline concentration could have resulted in active intrarenal vasoconstriction. ${ }^{12}$ In fact, an inverse relationship between plasma noradrenaline concentration and mean renal blood flow, as measured by the ${ }^{113} \mathrm{Xe}$ washout method, has been reported in recumbent patients with decompensated cirrhosis. ${ }^{22}$

The significantly higher increase of plasma renin activity can be attributed to both increased sympathetic activity and the activation of the 'tubulo-glomerular feed-back'. In fact in this and other studies ${ }^{1013}$ a positive correlation between plasma noradrenaline concentration and plasma renin activity was found under basal conditions. Furthermore beta-blocking drugs suppressed plasma renin activity proportionally to the height of the initial values in cirrhotics with ascites. ${ }^{23}$ Increased sympathetic activity can therefore be considered an important factor in the activation of the renin-angiotensin system in cirrhosis. The lack of correlation between plasma noradrenaline concentration and plasma renin activity sums of difference does not rule out the role of the adrenergic system, as the time course of the 

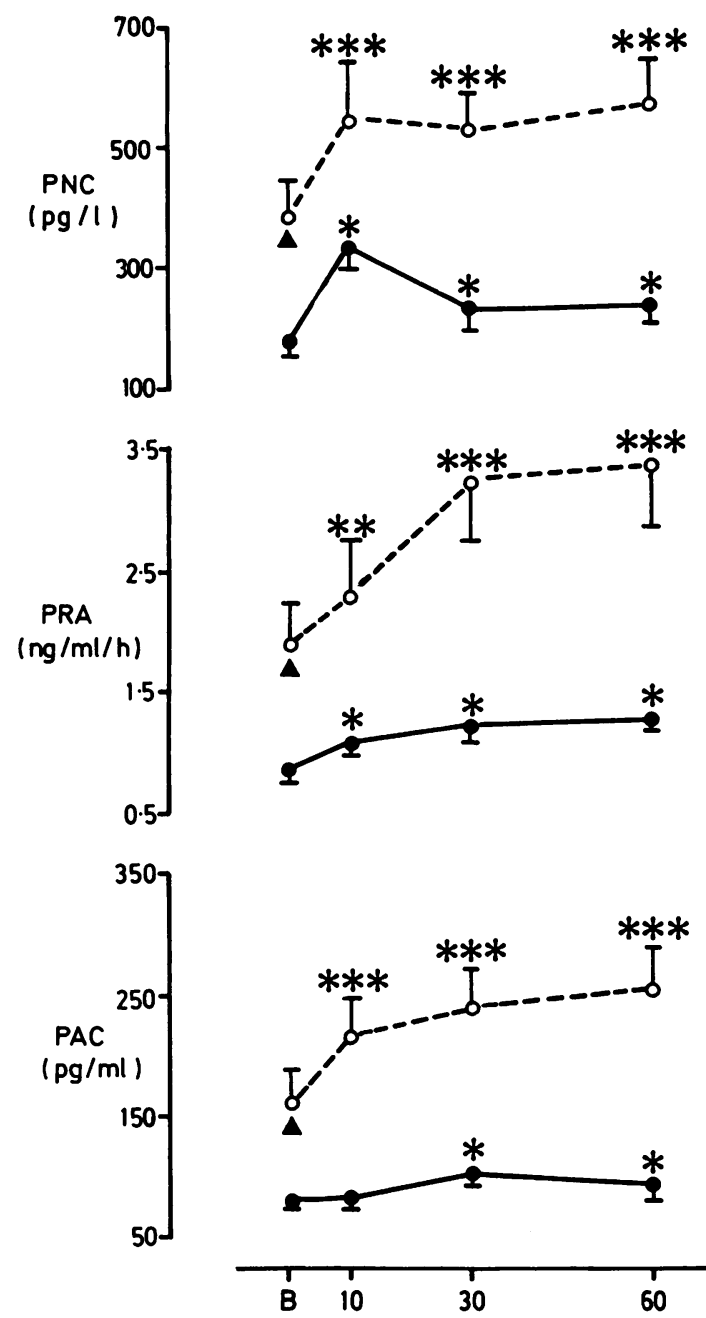

Fig. 2 Showing the time course of changes in PNC, PRA and $P A C$ after the change in posture. $\bullet-\bullet$, controls; 0 .- -, cirrhotics; ${ }^{*} p<0.05 ;{ }^{* *} p<0.005 ;{ }^{* * *} p<0.001$ with respect to basal values; $\boldsymbol{\Delta}, p$ values with respect of controls are shown in Table 2.

activation of the two systems during tilting is different. ${ }^{3}$ It is difficult to state, therefore, whether the increase in plasma renin activity was cause or effect of the reduction in renal perfusion. A significant inverse relationship between filtered sodium and plasma renin activity was found in our patients, under basal conditions. More important, $\Delta \mathrm{F}_{\mathrm{Na}}$ was inversely correlated with $\log \Sigma \Delta$ plasma renin activity during the sitting posture. This suggests that renal hypoperfusion, by. reducing sodium delivery to the macula densa, ${ }^{24}$ was more likely the cause, rather than the effect, of juxtaglomerular apparatus stimulation. The vasoconstrictor effect of angiotensin II ${ }^{25}$ which closely correlated to plasma renin activity in cirrhosis, ${ }^{17}$ cannot be overlooked. In fact it has been shown that beta-blocking drugs can induce plasma renin activity suppression and increase glomerular filtration rate in case of diuretic-induced uraemia without volume depletion. ${ }^{26}$

As mentioned above, the second relevant consequence of the assumption of sitting position by patients was the significant further reduction in renal sodium excretion. This was inversely related to the plasma aldosterone concentration sum of differences, further supporting the concept that mineralocorticoid activity is the basic stimulus to renal sodium retention in cirrhosis, over a wide range of experimental conditions. ${ }^{8}$ The inverse relationship between plasma noradrenaline concentration and both tubular rejection fraction and urinary excretion of sodium observed by us under basal conditions agrees with the findings by Bichet et al. ${ }^{13}$ This suggests that the increased sympathetic tone could contribute to antinatriuresis by its action at the tubular epithelial level. ${ }^{27-29}$ Nevertheless a statistically significant correlation was not found between $\log \Sigma \Delta$ plasma noradrenaline concentration and both $\Delta \mathrm{TRF}_{\mathrm{Na}}$ and $\Delta \mathrm{U}_{\mathrm{Na}} \mathrm{V}$. A dissociation between changes in plasma noradrenaline concentration and renal sodium excretion in cirrhotics has also been reported after neck out immersion. ${ }^{30}$ In any case it cannot be excluded that the possible sodium retaining activity by noradrenaline could have been masked by the prevalent factors involved in renal sodium handling. ${ }^{31}$

Our observations could assume importance in the clinical context. A prolonged maintenance of upright posture could lead to significant strengthening of renal sodium retention. This would require larger doses of antimineralocorticoid drugs to counteract the increased aldosterone activity. ${ }^{32}$ Furthermore, when renal perfusion undergoes a severe reduction, sodium retention would also be a direct consequence of decreased glomerular filtration rate. ${ }^{33}$ The use of loop diuretics would then be necessary. Bed rest could therefore be considered as a rational, even if ancillary, complement for treatment of ascites in cirrhosis.

\section{References}

1 Wilkinson SP, Williams R. Renal failure, ascites and electrolyte disorders. In: Wright R, Alberti KGMM, Karran S, Millward-Sadler GH, eds. Liver and biliary 
disease. Philadelphia: Saunders, 1979: 1060-86.

2 Molzahn M, Dissman TH, Halim S et al. Orthostatic changes of haemodynamics, renal function, plasma catecholamines and plasma renin concentration in normal and hypertensive man. Clin Sci 1972; 42: 209-22.

3 Hesse B, Ring-Larsen K, Nielsen I et al. Renin stimulation by passive tilting: the influence of an antigravity suit on postural changes in plasma renin activity, plasma noradrenaline concentration and kidney function in normal man. Scand J Clin Lab Invest 1978; 38: 163-9.

4 Blythe WB. Captopril and renal autoregulation. $N$ Engl J Med 1983; 308: 390-1.

5 Cier JF. La physiologie du systeme renineangiotensine. J Physiol 1979; 75: 179-93.

6 Shroeder ET, Eich RH, Smulyan N et al. Plasma renin level in hepatic cirrhosis. Am J Med 1970; 40: 186-91.

7 Rosoff L, Zia P, Reynolds T et al. Studies of renin and aldosterone in cirrhotic patients with ascites. Gastroenterology 1975; 69: 698-705.

8 Wilkinson SP, Williams R. Renin-angiotensinaldosterone system in cirrhosis. Gut 1980; 21: 545-54.

9 Bernardi M, Trevisani F, Santini C et al. Impairment of blood pressure control in patients with liver cirrhosis during tilting. Study on adrenergic and reninangiotensin systems. Digestion 1982; 25: 124-30.

10 Bernardi M, Trevisani F, Santini C et al. Plasma norepinephrine, weak neutrotransmitters, and renin activity during active tilting in liver cirrhosis: relationship with cardiovascular homeostasis and renal function. Hepatology 1983; 3: 56-64.

11 Bernardi M, Trevisani F, Santini C et al. Aldosterone related blood volume expansion in cirrhosis before and during early phases of ascites formation. Gut 1983; 24: 761-6.

12 Ring-Larsen $\mathrm{H}$, Hesse B, Henriksen $\mathrm{H}$ et al. Sympathetic nervous activity and renal and systemic haemodynamics in cirrhosis: plasma norepinephrine concentration, hepatic extraction and renal release. Hepatology 1982; 2: 304-10.

13 Bichet DG, Van Putten VJ, Schrier RW. Potential role of increased sympathetic activity in impaired sodium and water excretion in cirrhosis. $N$ Engl J Med 1982; 307: 1552-7.

14 Renzini V, Brunori CA, Valori I. A sensitive and specific fluorimetric method for the determination of noradrenaline and adrenaline in human plasma. Clin Chim Acta 1970; 30: 587-94.

15 Davies R, Slater JDH, Forsling ML et al. The response of arginine vasopressine and plasma renin activity to postural changes in normal man, with observations on syncope. Clin Sci Mol Med 1976; 51: 267-74.

16 Murray JF, Dawson AN, Sherlock S. Circulatory changes in chronic liver disease. Am J Med 1958; 24: 358-67.

17 Kontos HA, Shapiro W, Page Mauck H et al. General and regional circulatory alterations in cirrhosis of the liver. Am J Med 1964; 37: 526-35.
18 Wilkinson SP, Smith IK, Clarke M et al. Intrarenal distribution of plasma flow in cirrhosis as measured by transit renography: relationship with plasma renin activity and sodium and water excretion. Clin Sci Mol Med 1977; 52: 469-75.

19 Wernze H, Spech HJ, Muller G. Studies on the activity of the renin-angiotensin aldosterone system (RAAS) in patients with cirrhosis of the liver. Klin Wochenschr 1978; 56: 389-97.

20 Willkinson SP, Jowett TP, Slater JDH et al. Renal retention of sodium in cirrhosis: nephron site and relation to aldosterone. Clin Sci 1979; 56: 169-72.

21 Ganong WF. Funzioni del sistema nervoso: vie efferenti ad effettori viscerali. In: Ganong WF, ed. Fisiologia medica. Padova: Piccin 1975: 152.

22 Ring-Larsen $\mathrm{H}$, Henriksen JH, Christensen NJ. Increased sympathetic activity in cirrhosis. [Letter] $N$ Engl J Med 1983; 308: 1029-30.

23 Wilkinson SP, Bernardi M, Smith IK, Jowett TP, Slater JDH, Williams R. Effect of beta-adrenergic blocking drugs on the renin-aldosterone system, sodium excretion, and renal haemodynamics in cirrhosis with ascites. Gastroenterology 1977; 73: 659-63.

24 Nash FD, Rostorfer HH, Bailie MB. Renin release: relation to renal sodium load and dissociation from haemodynamic changes. Circ Res 1968; 22: 473-87.

25 Myers BD, Deen WM, Brenner BM. Effect of norepinephrine and angiotensin II on the determinants of glomerular ultrafiltration and proximal tubule fluid reabsorption in the rat. Circ Res 1975; 37: 101-10.

26 Wilkinson SP, Bernardi M, Wheeler PG et al. Diuretic-induced renal impairment without volume depletion in cirrhosis: changes in the renin-angiotensin system and the effect of beta-adrenergic blockade. Postgrad Med J 1979; 55: 862-7.

27 Bello-Reuss E, Trevino DL, Gottshalk C. Effect of renal sympathetic nerve stimulation on proximal water and sodium reabsorption. J Clin Invest 1976; 57: 1104-7.

28 Prosnitz EH, DiBona GF. Effect of decreased renal sympathetic nerve activity on renal tubular sodium reabsorption. Am J Physiol 1978; 235: F557-63.

29 Johnson MD, Barger AC. Circulating catecholamines in control of renal electrolyte and water excretion. $\mathrm{Am}$ J Physiol 1981; 240: F192-9.

30 Epstein M. Increased sympathetic activity in cirrhosis. [Letter] N Engl J Med 1983; 308: 1030.

31 Bichet DG, Van Putten VJ, Schrier RW. Increased sympathetic activity in cirrhosis. [Letter] $N$ Engl $J$ Med 1983; 308: 1031.

32 Bernardi M, Servadei D, Trevisani F, Rusticali G, Gasbarrini G. Importance of plasma aldosterone concentration on natriuretic effect of spironolactone in patients with liver cirrhosis. Digestion 1985 (In press).

33 Wilkinson SP, Moodie H, Alam A, Williams R. Renal retention of sodium in cirrhosis and fulminant hepatic failure. Postgrad Med J 1975; 51: 527-31. 